\title{
The effects of cultural dimension on people's perception about security on public transport
}

\author{
A. Syam, D. Reeves \& A. Khan \\ School of Architecture and Planning, University of Auckland, \\ New Zealand
}

\begin{abstract}
With increasingly diverse urban populations; it is becoming important for those seeking to increase usage of public transport to understand and take account of differences between cultural groups to increase travel opportunities in an inclusive way. Research shows that perceptions of and feelings about security as well as actual experience affect people's patronage of public transport. Studies also show that perceptions differ between ethnic groups. This paper investigates the reasons for the differences using Hofstede's cultural dimensions (HCD). Hofstede's dimensions have been used widely in marketing and management studies to explain differences in consumer and employee behaviour in terms of cultural background. However, as far as the authors are aware, it has never been used to explain travel behaviour differences. This paper examines whether and how Hofstede's dimension can be used to explain the differences in travel behaviour, especially for security perception on public transport. Using secondary analysis of data from two studies in the UK the paper uses HCD to offer an explanation based on the cultural background of the differences between Asian and British people's perceptions about security on public transport. Using $\mathrm{HCD}$, an explanation for Asian people's preference for CCTV as an additional security is that since they come from countries with a high power distance, this affects their trust of authority. Based on this, people would think that CCTV provides independent evidence if something happens. Other dimensions can also be used to explain this phenomenon. Despite the limited data available, the findings show that HCD can be used to explain travel behaviour differences based on ethnicity/cultural background.
\end{abstract}

Keywords: cultural dimension, Hofstede, travel behaviour, security perception, public transport. 


\section{Introduction}

Diversity and difference have become increasingly important variables in planning and transport as the populations of cities and urban areas have become more diverse. The post-modernist approach to planning is based on the premise that diversity (culture, tradition and all forms of differences) are real and it is not effective to apply one universal value. In the previous modernist era planners often ignored culture in making plans despite cultural differences make people have different needs [1-3]. One of the different needs is a security concern while using public transport.

Studies have shown that there is a difference in the way cultural groups see security concerns addressed [4,5]. However, up to now the studies have not offered any explanation of these findings from a cultural perspective. Using Hofstede's cultural dimension, this paper seeks to offer an explanation from the findings of the studies. This paper reviews research on transport-safety-culture to identify where culture/ethnicity is an important explanatory variable.

Hofstede's dimensions have been extensively used to explain consumer behaviour in business management field and people behaviour in psychology [68]. For tourism studies, research has used Hofstede's dimensions to explain travel behaviour in the context of their tourism destination option $[9,10]$, not specifically to travel behaviour as a whole. The question posed in this paper is whether and how Hofstede's dimensions can be applied to travel behaviour in the same way it has been used in business management and psychology? To date there is no published research using Hofstede's dimensions to explain travel behaviour.

This paper has 6 parts. The first part is an introduction and discusses the aims of the paper; the second part talks about security issues in transport and the relation with culture. The third part reviews culture and Hostede's dimensions. Findings from two research studies will be discussed in part four. Part five and six are discussion and conclusion part.

\section{Security issue in transport}

Security has become an important issue in transport; and is demonstrated by the number of scholars that have addressed this issue [11-13]. These studies show that there are three crime locations, in the transportation system; (1) when passengers walk to transportation facilities, (2) where passengers are waiting for the bus or train, (3) and on the bus/train itself [14]. The way to the bus stop or train station is one location that is very prone to crime. Results of studies suggest a distance between the bus stop and settlement should be a maximum five minutes of walking. In addition, several research studies show that fear when walking toward the bus stop is strongly influenced by the built environment [1518]. Poor lighting and uninhabited buildings contribute to fear [17]. It is not much different when waiting for a bus/train at the bus stop or train station.

Meanwhile, the fear experienced by passengers on the bus is often due to feeling lack of privacy and supervision [19]. In addition, the cramped conditions 
on the bus at peak times make certain groups (women, young people, and older people) feel unsafe. Talking about women, many researchers have conducted research on the fear experienced by women when using transport system. They found that women's fear is greater than the fear experienced by men when travelling at night $[15,16,20-24]$.

How do we handle fear? There have been many studies that give recommendations about how to overcome fear. One of many recommendations is to intervene in the built environment by improving lighting in places which are perceived dangerous [18]. Additional security personnel at crime-prone locations such as at bus stops, train stations and on the public transport itself are believed to enhance a sense of security. In addition the use of technology to enhance security is also a common solution [25]. But does everyone feel the same effects of all possible interventions that could be done to improve safety in the transport system? According to the survey in the UK, there are differences in responses between minority and majority ethnic about the effective ways to improve security $[5,26]$. A Survey in 2004 in the UK showed that white people feel safer with the addition of security staff on the train, while Asian and Black (minority) people prefer the use of CCTV to improve their security.

The use of culture as one of the variables in the study of transportation, primarily the study of travel behaviour, is not a new thing. Several researchers have used ethnicity for their studies. A study by Bose and Jones [27] with foreign-born women samples in the U.S. showed that foreign born women travel fewer miles and fewer trips day to day but travel more for international trips than native born. Another study by Blumenberg [28] in Los Angeles used Southeast Asian, Hispanic, Black and Whites samples shows that Southeast Asian welfare recipients tend to rely on private vehicle. Although these studies show that ethnicity is a significant dependant variable, the studies do not offer any explanation. Yet it is the explanation which would enhance our understanding of how best to develop policies to increase the patronage of public transport in an inclusive way.

\section{Culture definitions}

There are many definitions of culture, Hofstede defines culture as 'mental programming' derived from the collective level that makes people different from others who are not the collective group member [29]. Culture is a system of values that is adopted by a society, family, school, workplace, and the wider community. Culture is developed through a value system that exists in the community which become the social norms that affect social behaviour [29]. In line with Hofstede's definition, House et al. [30] defines culture as "shared motives, values, beliefs, identities, and interpretations or meanings of significant events that result from common experiences of members of collectives and are transmitted across age generations" (p. 5). 


\subsection{Comparing cultures}

Cultural comparisons can depend on proxy variables [31] based on characteristics that such as nationality or birth place. Some researchers used this approach and established a theory about cultural differences across nation or societies $[29,30,32]$. One of the most prominent studies which look at crosscultures is Hofstede's cultural dimensions. Using samples from the multinational corporation, IBM, Hofstede identified four dimensions which he found to be common to and embedded in the cultural values of every nation he studied. These dimensions are power distance, individualism-collectivism, and masculinity-femininity and uncertainty avoidance. Later Hofstede added one dimension namely short-long term orientation

House [33] extended Hofstede's dimensions to nine dimensions. These are power distance, uncertainty avoidance, collectivism societal, collectivism ingroup, gender egalitarian, assertiveness, future orientation, performance orientation and humane orientation [30, 33]. Schwartz [34] constructed seven dimensions; conservatism, intellectual and affective autonomy, hierarchy, egalitarianism, mastery and harmony dimensions.

\subsection{Hofstede's dimensions}

\subsubsection{Power distance}

This dimension shows the consequence of inequality of power relations in the society. The power distance can occur in family, organization, school, and in the state. Power distance varies depending on the social, educational and occupation level. The inequality of power means that a powerless side becomes subordinate to a more powerful side. For example, relation between the state and citizens is reflected in the power distance level. In countries with high power distance the relation between powerless and powerful individual/organisation is not equal; the government, powerful side, becomes a patron for citizen, the powerless side. In countries with low power distance, the relationship between people is more equal and this makes for a good reciprocal relationship and social and political processes which are very active on both sides [36].

\subsubsection{Individualism vs. collectivism}

This dimension shows the individual in relation to society. For an individualistic society, the member of society puts their personal and family interest as the main goal above the group interest. In the collective society, the member gives their loyalty to their group and allows group interests above their personal interest. In this society, relationship between members is very close and it makes them emotionally attached. One way to identify whether the society is individualist or collective is to observe the size of the family. Collective societies have a big size family and individualist society has a small size family, or nucleus family [36].

\subsubsection{Masculinity vs. femininity}

This is a cultural dimension that is reflected in every society. And acknowledges that the roles people take and the approach they take will depend on the 
orientation of that society. For instance in a masculine society, men are believed to be more ambitious, competitive, aggressive and oriented to achievement. On the other hand, in a feminine society men should take more attention to quality of life than success of materiality. Its point of view is not based on sex, but more about the nature of the society.

\subsubsection{Uncertainty avoidance}

This is a cultural dimension that shows society's attitude when they face an unstructured, unclear, and unpredictable situation. People can avoid this uncertainty with technology, law and religion. Technology is used to assist in defending themselves from the uncertainties caused by nature, the law is used to defend themselves from the uncertainty of other's behaviour, and religion is used to accept the uncertainty that cannot be defended by them self.

\subsubsection{Short and long term orientation}

This orientation is based on Confucianism. There are four key principles of Confucianism; (1) Unequal relationship between people will make society more stable; (2) The family is the prototype of all social organizations; (3) Virtuous behaviour toward others consists of not treating others as one would not like to be treated oneself; and (4) Virtue with regard to one's task in life consists of trying to acquire skills and education, working hard, not spending more than necessary, being patient, and preserving [37]. The values contained in the long term orientation are: persistence, a relationship based on status, thrift, shame. Meanwhile, the values for the short term orientation are: personal stability, protecting the face, respect for tradition, gives greetings and gifts.

\subsubsection{Limitation of Hofstede's dimensions}

There are some critics of Hofstede's work. The criticisms have been made to Hofstede's research in terms of samples and methodology. Hofstede himself recognizes five criticisms of his work [37]. One of the most frequent criticisms is about unit of analysis that Hofstede used. In his work, he uses nation as unit analysis. Some scholars said the nation cannot represent the sub-cultures in a country. He agrees with that but argued that nations "are usually the only kind of units available for comparison, and they are better than nothing" [37]. Nation can be used as a variable that represents the culture if people in one nation share the same language, history, identity and institutional structure [38]. That makes the nation as the unit of analysis is acceptable. The next criticism is about his sample. Some people said that Hofstede's sample is not representative of national culture [7, 32, 34]. Schwartz [34, 35] argued that a manager is not a value carrier; teachers are a better sample because they are value carriers. Another criticism relates to the data itself. The original data was collected in 60's-70's which some argue makes the data "old and obsolete" [37]. Some other researchers said that Hofstede's dimensions cannot explain the cultural change [7]. They believed in the globalisation era cultural change take place rapidly. Hofstede argued that national culture is relatively stable over time and needs centuries to change the cultural root of a country [37]. 


\subsection{Why use Hofstede's dimensions?}

Even though Hofstede's has received criticism there are sound reasons why researchers have persisted in using the dimensions. First reason, Culture's Consequences [29] is an initial study which integrates constructs previously separated. Hofstede was the pioneer who provided a coherent framework for cultural classified and becomes a basic for other cross-cultural studies [7]. Secondly, the simplicity of Hofstede's dimensions makes it very easy to understand. His dimensions are clear, firm and have intuitive appeal that makes researchers use it in interdisciplinary study. Thirdly, the classification in Culture's Consequences provides instruments to measure cultural values; Values Survey Module [29]. Thirty-three questions in values survey module drive us to assess cultural differences. With little modification in a range of disciplines, we can use this module for various purposes. Fourthly, Hofstede provides a set of extensive data for empirical analysis that attracts others to study the cultural differences.

\section{Data}

This paper uses data from two studies, The Department for Transport study in 2004 assessed people's perceptions of personal security and their concerns about crime on public transport and The Home Office Research study in 2001 tried to assess minority ethnic experiences based on British Crime Survey in 2000. This paper focuses on the findings about minority ethnic communities' experiences and perceptions of security in public transport.

The key findings from those studies were:

- Minority ethnic groups face greater fear of crime than white people.

- White people were more likely to contact the police than minority ethnics.

- Asian was least satisfied about police response after they reported a crime.

- Dissatisfaction about police efforts to keep them informed after their report was bigger amongst Asian people (Pakistanis and Bangladeshis).

- Of those experiencing incidents, $20 \%$ of Asian and only $14 \%$ of black respondents reported the incidents, compares to $24 \%$ of white respondents.

- For Asian, black and minority ethnic, the main reason for not reporting is that they 'did not think they would be taken seriously' (38\%). For white victims the main reason for not reporting is because they considered it was 'not serious enough' (40\%). Asian, black and minority are less likely to report an incident they have seen but not directly experienced, again mainly for the reason that they would not be taken seriously.

- Irrespective of ethnic group, CCTV surveillance is first choice for people feeling more secure while waiting at a bus stop or shelter.

- For all ethnic groups CCTV surveillance is favored to enhance security while traveling on the bus. Second choice is the presence of a member of staff in addition to the driver.

- $\quad$ For Asian the first choice while waiting for a train is CCTV (38\%), followed by the presence of staff and then good lighting; while for black respondents it is the presence of staff (35\%), followed by CCTV and good lighting. 
- Asian, black and minority ethnic respondents favor CCTV surveillance for personal security on trains, while their white counterparts prefer having a guard or conductor walking through the train $[4,26]$.

Because this paper uses data from other studies it will use secondary data analysis method to examine the differences between minority (Asian people) and majority ethnic (white people). Using data from previous studies this paper will use Hofstede's dimension to explain why the differences occur. The first step is comparing Asian countries cultural index with the UK and then explain research findings using cultural dimension.

\section{Discussion: the differences in security perception}

The survey conducted by the Department for Transport (DfT) in 2004 shows that there were different perceptions about safety in using public transport. For security systems at the bus stop or shelter, all ethnic groups choose CCTV as a tool that can improve security when they are there. For travelling by bus, all ethnic groups also preferred CCTV as an additional safety device and followed by additional staff on the bus. Differences are seen in their choice of additional security devices required at the train station. Thirty-eight percent of Asian people choose CCTV followed by additional staff as an option that makes them feel safer. While 35\% Black people choose additional staff as an option that makes them feel safer in the train station followed by CCTV and good lighting. Unfortunately there is no data on White people's perception at train station. For feelings of additional security on trains, Asian, Black and minority ethnic groups choose CCTV as added security devices that made them feel safer. While Whites choose additional staff as the main tool that can provide them additional security. Additional staffs that walk through the train can make them feel more secure.

Using cultural dimensions, the perception differences can be explained. Power distance is useful for this phenomenon. Asian countries in Hofstede's index have high power distance, this means relations between citizens and authority is not equal. This can lead to a distrust of authority. This means people don't trust the authority. It is common in Asian countries that the authority corrupts their power. If we refer to corruption perception index by Transparency International, in 2009 only Singapore, Hong Kong, Japan, Qatar, United Arab Emirate, Taiwan, Brunei, Oman and South Korea included in 40 countries with low corruption rates. Other Asian countries have high rates. This is in line with Hofstede's power distance index. Corruption on those countries is high because there is no check and balance from citizen to their government because from childhood they have been taught to follow their leader, this is called patron-client relation. It makes them think that the government can manipulate the law.

In relation to DfT research, Asian/Africa people prefer to have CCTV on trains because recordings from CCTV give them evidence if something occurs. Therefore, the authority cannot "play cat and mouse" because there is evidence. The victim of the crime doesn't have to give a long argument because CCTV recording can give police or court evidence that they need. White people prefer additional officers because they are confident that the officer will treat them 
equal. From power distance index, Great Britain has low power distance index contrasting with Asian countries. The lowest score in this region is Japan with score 54 and the highest score is Malaysia with 104. According to Hofstede, low power distance countries treat their citizen equally. Citizens have a right to question their government policy and the government has an obligation to give their citizens good service including answering people's question about their policy. The "check and balance" opportunity makes people have a high trust to the authority. That makes them confident that every officer will treat them equal and give them protection if they need it. That is why White people favour additional officer as a tool that can improve their safety feelings.

In addition, people who come from high uncertainty avoidance countries think CCTV can give them a certainty about their status if they become a victim of crime. That is why Asian people prefer CCTV as additional security in all modes of transport. Asian countries have difference UA score, but if we look at Hofstede's index, Asian countries have high and medium range score except Singapore which is have a very low score (see table 1). Unfortunately, DfT study does not give us information about Asian samples country of origin. But if we refer to the Home Office Research study [4], they used South Asia population including Indian, Pakistani and Bangladeshi as Asian samples. Chinese samples were taking into account but very small. These South Asia countries have high PD and UA score (see table 1). It makes CCTV become their first choice.

Table 1: $\quad$ Hofstede's index for Asian countries and Great Britain.

\begin{tabular}{|c|c|c|c|c|c|c|c|c|c|c|c|}
\hline Countries & PD & IC & MF & UA & SL & Countries & PD & IC & MF & UA & SL \\
\hline $\begin{array}{c}\text { Arab } \\
\text { countries }\end{array}$ & 80 & 38 & 53 & 68 & 23 & Malaysia & 104 & 26 & 50 & 36 & 100 \\
\hline Bangladesh & 80 & 20 & 55 & 55 & 47 & Pakistan & 55 & 14 & 50 & 70 & 41 \\
\hline China & 80 & 20 & 66 & 30 & 87 & Philippines & 94 & 32 & 64 & 44 & 50 \\
\hline Hong Kong & 68 & 25 & 57 & 29 & 61 & Singapore & 74 & 20 & 48 & 8 & 27 \\
\hline India & 77 & 48 & 56 & 40 & 51 & Taiwan & 58 & 17 & 45 & 69 & 72 \\
\hline Indonesia & 78 & 14 & 46 & 48 & 62 & Thailand & 64 & 20 & 34 & 64 & 93 \\
\hline Iran & 58 & 41 & 43 & 59 & 14 & Vietnam & 70 & 20 & 40 & 30 & 32 \\
\hline Japan & 54 & 46 & 95 & 92 & 25 & $\begin{array}{c}\text { Great } \\
\text { Britain }\end{array}$ & 35 & 89 & 66 & 35 & 57 \\
\hline South Korea & 60 & 18 & 39 & 85 & 88 & & & & &
\end{tabular}

Source: http://www.geerthofstede.com (accessed 16/08/2010).

PD : Power Distance IC : Individualism-collectivism MF : Masculinity-femininity UA : Uncertainty Avoidance SL : Short-Long term orientation

Another interesting result from this survey is the low percentage of Asian $(20 \%)$ and Black (14\%) people who reported incidents of violence that they see on public transport to the police. Compared with $24 \%$ of white people who reported what they see to the police. Further investigation showed that thirtyeight percent of the reason why Asian, Black and ethnic minority did not report 
the incident because they "did not think they would be taken seriously" [26, p.2]. From The Home Office Research Study (HORS) Asian people especially Pakistani and Bangladeshi are the ethnic groups that feel dissatisfied with police response to their report. Pakistani and Bangladeshi are from high PD societies, it makes them have a low trust on the apparatus shows by the statement "did not think they would be taken seriously".

Another finding also said that Asian, Black and minority ethnic will feel safer and welcome if officers display good attitudes such as smile and give a hand if they need it. It is about communication, verbal and body language. In the individualism-collectivism dimension, Hofstede explains people from collective society tend to use high-context communication. It means that a person does not need to speak much because their body language and expressions considered have been able to convey messages to others. People from this society mainly use a very gentle tone when speaking to other people. Asian countries according to individualism-collectivism index are categorised into collective culture, the score range between 48-14 (see table 1). That is why Asian people greatly appreciate people's expression and body language. The officer who gives smile to people will make passenger feel safer and welcome.

The high-context communication approach also can be used to explain a case where only a few Asian, Black, and ethnic minority who reported the incident to the police they had seen. People from high-context communication society will translate assertive tone and expression of the police as unusual/impolite communication and will make them feel offended and threatened. This factor makes them avoid to report or make contact with policeman if they are not the victims. Furthermore, language barrier might influence the reason why Asian people prefer CCTV. They might not be able to communicate their situation if they feel threatening. CCTV assures them there is a preventive action without even say a word. According to the DfT studies, people feel more secure with CCTV because they know that someone watching them.

Overall, the data shows differences on people's perception in different places. People have similar perception about security in the bus stop and on the bus, but they have a difference perception in the train station and on the train. It might because the condition of bus stops relatively small so CCTV is considered enough as additional security to monitor the place. It makes additional staff is not an option in this place. It is different to train station; it is bigger than bus stop so people might think it needs more than CCTV to watch a whole area that makes them feels safer. CCTV is also considered has a blind spot that makes additional staff is required to cover that spot in the larger place.

\subsection{Limitations of this paper}

The paper is based on secondary data analysis of other studies. Unfortunately, the studies were not designed specifically to examine the reasons for behavioural differences. The studies only intended to capture security perception differences between ethnics group not explain it. It makes the paper faces the difficulty to produce more complete and comprehensive explanation using HCD. 


\section{Conclusion}

From the explanation above it can be concluded that Hofstede's cultural dimensions can offer an alternative to explain the phenomenon of minority ethnic groups' perception about security on the public transport that differ from majority. Not all of Hofstede's dimensions can be applied to explain perception differences on security issue. The use of Hofstede's dimension depends on the issues to be assessed. The paper demonstrates the potential use of Hofstede's dimensions in explaining other areas of transport including travel needs, travel desire even transport policy pattern from a country. Ethnicity/culture is not the only factor that can affect people's perception or travel behavior. There are several other variables that can be used to explain this phenomenon. For example, we must consider the economic aspects that can affect crime rates that immigrants/minorities experienced. Immigrants/minorities tend to live in low income condition. This condition occurs because they are engaged in non-formal employment and underpaid [39]. This forced them to live in the inner city with statistically has a high crime rate [4]. Culture is used because of its ability to explain the area that has not yet received attention in the transport study.

\section{References}

[1] Burayidi, M.A., Urban planning in a multicultural society, Westport, CT: Praeger. x, 264 p, 1999

[2] Qadeer, M.A., Pluralistic Planning for Multicultural Cities: The Canadian Practice. Journal of the American Planning Association, 63(4): p. $481-494,1997$.

[3] Sandercock, L., Planning in the Ethno-culturally Diverse City: A Comment. Planning Theory \& Practice, 4(3): p. 319-323, 2003.

[4] Clancy, A., Hough, M., Aust, R., Kershaw, C., Crime, Policing and Justice: The Experience of Ethnic Minorities Findings from the 2000 British Crime Survey. National Criminal Justice Reference Service: London. p. 181, 2001.

[5] DfT, People's Perception of Personal Security and Their Concerns About Crime on Public Transport: Research Findings. Department for Transport: London. p. iii+109, 2004.

[6] Ayoun, B.M. and P.J. Moreo, The influence of the cultural dimension of uncertainty avoidance on business strategy development: A cross-national study of hotel managers. International Journal of Hospitality Management, 27(1): p. 65-75, 2008.

[7] Soares, A.M., M. Farhangmehr, and A. Shoham, Hofstede's dimensions of culture in international marketing studies. Journal of Business Research, 60(3): p. 277-284, 2007.

[8] Steenkamp, J.-B.E.M., F.t. Hofstede, and M. Wedel, A Cross-National Investigation into the Individual and National Cultural Antecedents of Consumer Innovativeness. The Journal of Marketing, 63(2): p. 55-69, 1999. 
[9] Hough, G. and A. Hassanien, Transport choice behaviour of Chinese and Australian tourists in Scotland. Research in Transportation Economics, 26(1): p. 54-65, 2010.

[10] Xu, F., M. Morgan, and P. Song, Students' travel behaviour: a cross-cultural comparison of UK and China. International Journal of Tourism Research, 11(3): p. 255-268, 2009.

[11] Carter, M. Gender Differences in Experience with and Fear of Crime in Relation to Public Transport (abstract only). Proc. Of the Conf. On Research on Women's Issues in Transportation, eds. Committee on Research on Women's Issues in Transportation, Transportation Research Board: Washington, DC, p. 100, 2004.

[12] Gaetz, S., Safe Streets for Whom? Homeless Youth, Social Exclusion, and Criminal Victimization. Canadian Journal of Criminology and Criminal Justice/La Revue canadienne de criminologie et de justice pénale, 46(4): p. 423-456, 2004.

[13] Smith, M.J. and R.V. Clarke, Crime and Public Transport. Crime and Justice, 27 (2000): p. 169-233, 2000.

[14] DfT, Links between Bus-Related Crime and Other Crimes: A Briefing Paper. Department for Transport: London, 2004.

[15] Koskela, H., 'Gendered Exclusions': Women's Fear of Violence and Changing Relations to Space. Geografiska Annaler. Series B, Human Geography, 81(2): p. 111-124, 1999.

[16] Koskela, H. and R. Pain, Revisiting fear and place: women's fear of attack and the built environment. Geoforum, 31(2): p. 269-280, 2000.

[17] Loukaitou-Sideris, A. Is It Safe to Walk Here? Design and Policy Responses to Women's Fear of Victimization in Public Places. Proc. Of the Conf. On Research on Women's Issues in Transportation, eds. Committee on Research on Women's Issues in Transportation, Transportation Research Board: Washington, DC, p. 102-112, 2004.

[18] Painter, K., The influence of street lighting improvements on crime, fear and pedestrian street use, after dark. Landscape and Urban Planning, 35(2-3): p. 193-201, 1996.

[19] Parolin, B., The effects of social heterogeneity on travel patterns: A replication study. Socio-Economic Planning Sciences, 26(4): p. 231-239, 1992.

[20] Madge, C., Public Parks and the Geography of Fear. Tijdschrift voor economische en sociale geografie, 88(3): p. 237-250, 1997.

[21] Pain, R., Gender, Race, Age and Fear in the City. Urban Studies, 38(5/6): p. 899-914, 2001.

[22] Pain, R.H., Social Geographies of Women's Fear of Crime. Transactions of the Institute of British Geographers, 22(2): p. 231-244, 1997.

[23] Stanko, E.A., Women, Crime, and Fear. Annals of the American Academy of Political and Social Science, 539(1995): p. 46-58, 1995.

[24] Valentine, G. The Geography of Women's Fear. Area, 21(4): p. 385-390, 1989. 
[25] Bomar, M.A. Technology as a Strategy for Addressing Personal Security Concerns of Women on Public Transit. Proc. Of the Conf. On Research on Women's Issues in Transportation, eds. Committee on Research on Women's Issues in Transportation, Transportation Research Board: Washington, DC, p. 101, 2004.

[26] DfT, People's Perception of Personal Security and Their Concerns about Crime on Public Transport: Fact Sheet 7 Black and Minority Ethnic Communities, Experiences and Perception. Department for Transport: London, 2004

[27] Bose, J., \& Jones, June T. Travel Characteristic of Native- and Foreign Born Women in the United States. Proc. Of the Conf. On Research on Women's Issues in Transportation, eds. Committee on Research on Women's Issues in Transportation, Transportation Research Board: Washington, DC, p. 3, 2004.

[28] Blumenberg, E., Immigrants and transport barriers to employment: The case of Southeast Asian welfare recipients in California. Transport Policy, 15(1): p. 33-42, 2008

[29] Hofstede, G.H., Culture's consequences: international differences in workrelated values. Cross cultural research and methodology series, Beverly Hills, Calif.: Sage Publications. 475 p, 1980.

[30] House, R., et al., Understanding cultures and implicit leadership theories across the globe: an introduction to project GLOBE. Journal of World Business, 37(1): p. 3-10, 2002.

[31] Lenartowicz, T. and K. Roth, A Framework for Culture Assessment. Journal of International Business Studies, 30(4): p. 781-798, 1999.

[32] Schwartz, S.H. and A. Bardi, Value Hierarchies across Cultures. Journal of Cross-Cultural Psychology, 32(3): p. 268-290, 2001.

[33] House, R.J. and Global Leadership and Organizational Behavior Effectiveness Research Program., Culture, leadership, and organizations: the GLOBE study of 62 societies, Thousand Oaks, CA: Sage Publications. xxviii, 818 p, 2004,

[34] Schwartz, S.H., Beyond Individualism/Collectivism. New Cultural Dimensions of Values, in Individualism and Collectivism: Theory, Method, and Applications, U. Kim and Han*guk Simni Hakhoe., Editors. Sage Publications: Thousand Oaks, Calif. p. xix, p. 338, 1994,

[35] Schwartz, S.H., A theory of cultural values and some implications for work. Applied Psychology: An International Review, 48(1): p. 23-47, 1999.

[36] Hofstede, G.H., Cultures and organizations: software of the mind, London; New York: McGraw-Hill. xii, 279 p, 1991,

[37] Hofstede, G., Culture's consequences: comparing values, behaviors, institutions, and organizations across nations. 2nd ed. ed., Thousand Oaks, Calif ; London: SAGE. xx, 595 p, 2001

[38] Hofstede, G., Cultural dimensions in management and planning. Asia Pacific Journal of Management, 1(2): p. 81-99, 1984.

[39] Wills, J., Global cities at work: new migrant divisions of labour. England: Pluto Press. xiii, 234 p, 2010. 